\title{
Discourse Socialization in Synchronous Computer-Mediated Communication
}

\author{
Myung-Jeong Ha \\ Department of English Language and Literature \\ Sangmyung University, Cheonan, 330-720, South Korea
}

\begin{abstract}
This paper, based on a qualitative ethnographic study among college of education students, examines the online interactional processes surrounding academic discourse socialization. Data for this paper come from a larger study of an academic classroom community of graduate students and their instructor. In this study, I looked into the ways computer-mediated communication (CMC) contexts factor into graduate students' academic literacy experience in a graduate classroom, therein enculturating them into their new academic community. I focus on cases of nonnative graduate students in a content course in the department of educational psychology at a large southwestern university in the U.S. I explore the agency of the focal participants in terms of the roles they played in the classroom discourse highlighting the dialectical and interactional perspective of academic discourse socialization. This paper focused on the construction of varied participant roles of the focal students. It further examines student reactions and responses to these constructions during synchronous CMC activity.
\end{abstract}

Key words: Computer-Mediated Communication, Discourse Socialization, Online Interaction, Community of Practice.

\section{INTRODUCTION}

Some scholars have conceptualized learning as coming to know how to participate in the discourse and practices of a particular community (e.g. [1], [2]). In this view, individual graduate students participate in numerous academic communities, ranging from scholarly disciplines to groups of people sharing a common academic interest, to particular classrooms. These communities provide cognitive tools that students adopt and appropriate as their own through their personal efforts to make sense of academic literacy experiences.

From a social perspective, a central goal of higher education is to familiarize students with various academic communities, equipping them with literacy competency in using the concepts and the forms of reasoning and argument that characterize those communities [3]. This perspective leads to the question of what kinds of discourse communities are established in graduate classes that prepare students who aspire to become fuller members of a specific discipline. Swales [4] suggested that although an academic class is unlikely to be a discourse community at the outset, the "hoped-for outcome is that it will form a discourse community" (p. 32). Mercer [5], drawing on the work of Swales [4] as well as the work of Lave and Wenger [2], also speculated about the potential of thinking about community in relation to schooling. Inspired by the work of these scholars, I saw graduate learning in this study as being as much a matter of enculturation into a community's ways of

\footnotetext{
* Corresponding author,Email: mjha@smu.ac.kr Manuscript received Apr. 09, 2013; revised Jul 16, 2013; accepted Aug 01, 2013
}

thinking and dispositions as being the result of explicit instruction in specific concepts, skills, and procedures.

As for the contours of graduate education, Prior [6] explained that "students' production of texts, and professor and peer response to those texts are activities central to "academic discourse socialization because these activities provide an opportunity space for socialization into discursive practices, represent a central medium for the display of disciplinarity, and mediate the reproduction of disciplinary social structures as students achieve relative levels of success and visibility" (p. 489). Of crucial importance is learners' participation in academic literacy events, given that literacy practices penetrate academic learning across disciplinary fields.

Such learning is more familiar to proponents of the participation metaphor that examines academic learning as a process of participation in various cultural practices and shared learning activities. Adherents of the participation metaphor are focused on activities (knowing) rather than on outcomes or products (knowledge) [7]. In this vein, both knowledge and knowing cannot be separated from situations where they are used or where they take place, and academic learning is seen as a matter of participation in practices and actions "enculturation" [8], "academic discourse socialization" [9], or "legitimate peripheral participation" [2].

The "situatedness" of learning and cognition has been described by several researchers including [10], [2]. The idea of cognitive apprenticeship, that a learner typically acquires new skills by being an apprentice under the guidance of a master, is a basic idea of the theory of situated learning. Lave and Wenger's [2] notion of legitimate peripheral participation expanded this concept by highlighting the impact on the 
learning outcome of factors such as the fruitfulness of the relationship between the learner and the master, the role of the community in which the learner seeks membership, and whether the learner is an active participant in the learning community.

Second, in recent L2 literature, there has been a growing call for an approach that permeates the multiplicity of discourses, perspectives, and realities in a given social context. As Brown and Duguid [11] stated, "Practice is an effective teacher and community of practice is an ideal learning environment" (p. 127). Learning from a "community of practice" perspective is congruent with notions of situated cognition, where contextsthe social practice and activity structures underpinning the practice - are fundamentally interwoven with cognition and learning.

Third, the exploration of the process of gaining membership in an academic discourse community is wholly developed on a foundation of academic literacy, context and nature of language in a discipline, expertise and expert communities, and the expert academic writer in disciplinary communities. Academic socialization of novice graduate students into discourse communities is thus a lengthy process that can be "transformative" [12], suggesting that a process-oriented approach is more appropriate in capturing how learners change over time. Furthermore, academic discourse socialization refers not only to novices being initiated, but also to the continual processes whereby relative newcomers and relative old-timers reproduce and re-invent themselves, their practices, and their communities [13].

In higher education, many researchers have explored the academic discourse socialization of L2 university students, particularly through writing. Many of the studies on academic discourse socialization (e.g., [13] - [15]) has heavily turned to writing literacy activities (e.g, academic genre writing), with a handful of studies (e.g., [9], [16]) about oral activities (e.g., conference presentation). Several studies have examined the implications of student-supervisor interpersonal and textual interactions in students' efforts at producing writing acceptable to their target research community [14], [17], [18]. Other studies have documented how newcomer students' proactive participation in their learning community can lead to the success of their academic discourse socialization [14], [19].

However, these studies have mainly focused on hierarchical and dyadic relationships between students and the professor (or mentor) in relation to the printed texts; there has been little exploration into academic discourse socialization in online community contexts where a more equal distribution of power and authority occurs among participants.

In their academic life, one of the basic premises for transnationalized higher education is to develop academic literacy and communication skills in computer-mediated discourse, which is a key to meet the challenges of the present and future academic, social and workforce spaces in this borderless academic world [20]. Indeed, computer-mediated communication (CMC) has become integral parts of higher education [21] particularly in Australia, Canada, the United Kingdom, and the United States [22]. There is thus a growing need to examine L2 learners' academic socialization through their participation in computer-mediated academic literacy practices. The goal of this study is to explore the repertoire of participant roles in synchronous CMC that is grounded in academic discourse socialization.

In this study, I investigated the discourse socialization of L2 graduate learners by employing a qualitative, process-oriented approach. My study documented the initial period of this process, that is, during the first semester of novices' graduate studies. By employing a community of practice perspective [2], my study was an attempt to demonstrate how CMC space mediates L2 learners' academic discourse socialization and is closely related to issues of agency.

\section{SIGNIFICANCE OF THE STUDY}

Although much of the previous L2 literature in the area of academic discourse socialization has mainly turned to academic writing activities and oral presentations, this study makes contributions by investigating the nature of academic online discourses, with a focus on online group discussions in a graduate content course. By doing so, my study attempts to make a significant bridge between computer-mediated communication and academic discourse socialization. In classroom settings, many studies on $\mathrm{CMC}$ during the last decade have focused on the benefits of CMC regarding its function that can change traditional power structures in the classroom and provide learning opportunities for students. However, very few CMC studies in higher education contexts attempted to explore L2 learners' academic discourse socialization through online discussions (for an exception see [23]).

Earlier L2 research investigated CMC primarily through the lenses of previous forms of spoken or written interaction. My study attempts to provide a better understanding of how the affordances of computer communication problematize some of the earlier notions of interaction, identity, and literacy within an academic classroom community, inspired by the recent trends of academic literacy highlighting that a focus on language and literacy development as situated social processes ... involves understanding the acquisition of language and literacies as always occurring in and through interactions with others in specific contexts ([24], p. 60).

Furthermore, the findings of the study should be of interest to a critical line of research that explores L2 academic socialization through classroom activities within content courses.

This study suggests that educators in higher education should use computer technology not so much to teach the same thing in a different way, but rather to help students enter into a new realm of "intersubjective meaning-making" [25], viewing their expanding repertoire of identities and communication strategies as resources in an academic discourse socialization process. The study presented here contributes to this growing body of $\mathrm{CMC}$ research by employing the notion of communities of practice [2] to illustrate and explain the complex and dynamic ways that non-native novice students negotiated their academic participation in their graduate class. In synchronous chat, firstyear graduate students learned to become full participants in the graduate school community of practice by getting acquainted 
with the language and tasks of their academic community.

Contributing to a progression of recent L2 scholarship that has examined the connections between linguistic development, sociocultural contexts and relationships [15], this study concentrates on the ways ESL graduate students' academic literacy competencies are thriving in the computer-mediated discourse that links with larger social, rhetorical, and cultural contexts and then shapes their academic participation.

Although academic socialization certainly concerns broad disciplinary norms and conventions, this study focuses on the more locally situated and immediately created web of interactions and relationships that can either constrict or support learners' academic participation. Accordingly, this study enriches notions of legitimate peripheral participants [2] by exploring how they, as much as the computer-mediated discourse they produce, are situated in socially, culturally, and rhetorically complex fields of academic literacy practice.

\section{METHOD}

\subsection{Participants}

This study was conducted at a large research university located in a multilingual city in southwestern United States. The participants of the study were graduate students who took a graduate content course offered by the graduate program in Educational Psychology. Of the 31 students enrolled in the course, 22 were female students and 9 were male students. Among those 31 students, there were 10 non-native English speakers. With a total of 31 students enrolled in the class, 10 were non-native students. The current study concerns three first-year ESL graduate students acquiring a disciplinary discourse of educational psychology in a mainstream classroom community. The main focal participants were female graduate students who came from Taiwan, Mexico, and Puerto Rico.

\subsection{Data Collection}

My study incorporated classroom observations, background questionnaires, end-of-semester questionnaires, print outs of CMC texts, ethnographic in-depth interviews with the focal students and the teacher interview, copies of course-related documents, students' self-reflective essays about online discussions, and my reflective research journal. Such incorporations have enabled me to create a "thick description" of the emergent community of practice in the online space as well as to gain a rich sense of what it means to become enculturated in the new academic discourse.

3.2.1 CMC Written Texts: After each online discussion, I collected the transcript of the online discussion. I examined the transcripts from a language socialization perspective and with the concepts of a community of practice in mind prior to the discourse-based interviews.

3.2.2 Interviews: I conducted interviews with the focal students within a week of a synchronous online discussion. Informed by both of discourse-based and ethnographic interviews, I interviewed each of the five participants four times over the fall semester.
3.2.3 Self-Reflective Essays: Students were asked to produce a self-reflective essay on the online discussions as part of the class assignments, with the purpose of helping them reflect on what they had learned by engaging in CMC written discussions.

\subsection{Data Analysis}

Although data were collected in the whole class activities from beginning to end, this study focused on describing and interpreting the focal students' academic discourse socialization mediated by online discussions. I chose a specific online task, synchronous $\mathrm{CMC}$ discussion, as the primary focus of analysis in this study.

For the $\mathrm{CMC}$ written texts, I drew on interactional sociolinguistics to examine how academic discursive practice is interrelated to the construction of learner agency and social relationships in the electronic exchanges produced by the focal students and their interlocutors. As the goal of my inquiry lay in describing the focal students' evolving participant roles, my analysis was widely guided by Goffman [26] and Larson [27].

\section{RESULTS AND DISCUSSION}

\subsection{Quantification of Postings}

To gain a better understanding of the level of participation, I first counted the total number of synchronous chat postings and total asynchronous Blackboard postings created by the focal participants. Table I below displays the relative breakdown of postings simply as number of postings.

As Table 1 illustrates, three focal participants, Rua, Lynn, and Kelly, produced an almost equal numbers of postings.

Table 1. Online Postings for the Focal Participants

\begin{tabular}{|c|c|c|c|c|c|}
\hline & \multicolumn{3}{|c|}{ Synchronous CMC } & \multicolumn{2}{|c|}{ Asynchronous CMC } \\
\hline Students & $\begin{array}{l}\text { Total } \\
\text { number } \\
\text { of } \\
\text { postings }\end{array}$ & $\begin{array}{l}\text { Mean \# } \\
\text { per } \\
\text { discussion }\end{array}$ & $\begin{array}{l}\text { Number } \\
\text { of } \\
\text { postings } \\
\text { excluding } \\
\text { initial } \\
\text { salutations }\end{array}$ & $\begin{array}{l}\text { Total } \\
\text { number } \\
\text { of } \\
\text { postings }\end{array}$ & $\begin{array}{l}\text { Mean \# } \\
\text { per } \\
\text { discussion }\end{array}$ \\
\hline Rua & 27 & 6.7 & 24 & 11 & 3.6 \\
\hline Lynn & 28 & 7.0 & 24 & 11 & 3.6 \\
\hline Kelly & 27 & 6.7 & 23 & 10 & 3.3 \\
\hline
\end{tabular}

Note. Mean of rest of class in each online chat: 10.7

\subsection{Participant Roles Performed by Focal Students}

Several participant roles were identified in synchronous chat activity: primary author, respondent, agreer, commenter, questioner, challenger, and pivot. The primary author is a speaker who made a basic comment to begin a discussion by presenting a certain view about the topic under consideration. The respondent role can be taken by more than one interactant who answer questions posed to the participants by the primary author. By performing agreer role, interactants display their agreement in response to a previous contribution. In the role of commenter, participants commented on the primary author's opinion. Questioner is a role in which participants pose some question in relation to a previous posting for various purposes such as comprehension check, request for help, ask for 
confirmation, and clarification. The challenger role was identified when interactants showed their disagreement with an other interactants' statement.

The role of pivot was employed whenever a participant took "information or knowledge from one dyadic interaction and carrie[d] it into the creation of another dyad, thereby facilitating the knowledge circulation process and expanding the participation framework" [27].

Table 2 shows variations in participant roles taken by the focal students during online chat sessions. In what follows, I discuss the participant roles performed by the focal students in synchronous CMC activity.

Table 2. Participant Roles Performed by Focal Students

\begin{tabular}{llll}
\hline Roles & Rua & Lynn & Kelly \\
\hline Primary author & 0 & 0 & 0 \\
Respondent & 2 & 3 & 5 \\
Agreer & 0 & 12 & 0 \\
Commenter & 9 & 2 & 12 \\
Pivot & 1 & 1 & 5 \\
Questioner & 12 & 3 & 1 \\
Challenger & 0 & 3 & 0 \\
\hline
\end{tabular}

4.2.1 Kelly's Perspectives and Agency: The first interview showed that Kelly was interested in participating in synchronous chat although she felt "a little bit nervous." When asked how she felt about her first experience in chat, she said:

"I thought it was an interesting idea that I liked, the idea of having different styles of discussion in the class sort of experiencing different ways of materials. I think I was ... I was interested in that and then I was a little bit nervous because I didn't know what to expect, you know. It definitely felt like, um, you're little more on the spot than, say, in the classroom discussion where you may choose to talk or not to talk, you definitely include something in there and contribute something, you know.” (Interview, September 23, 2009)

Kelly had personal ideas about the purpose of having group chat discussions, which was to interact with others and to share others' ideas. She felt that the most difficult part of her participation in the chat was to keep track of what everyone was saying and then figure out ways to contribute to that discussion.

With regard to motivation, Kelly showed relatively higher motivation in chat discussions than classroom discussions. She felt more responsibility to keep the discussion going as an accountable member of a group.

"I think, ... I think I have a higher motivation in the chat because I think you you kind of have this feeling like you need to contribute to try a couple of times at least and to keep, you feel like I have a responsibility that to be part of keeping the conversation going, ummm, I think in class sometimes discussion can just happen between two or three people, you know, even one person with a professor, and then in the chat, I think you feel more responsible to be part of the group." (Interview, September 23, 2009)
By the second synchronous discussion, unlike other students, Kelly felt that she had become comfortable with the chat format, and with the process of jumping in and taking up or starting a thread while other students focused on different topics. I suggest that she became aware of "comfort zones of orality in which discourse is highly involved and personal" [16] in chatroom communication. With regard to her role in the class, it seemed that there was a certain degree of shift from an invisible listener's role to a visible speaker's role. In the following excerpt, her voice conveyed a sense of critical awareness in such a role shift:

"Yes, I would say that because I think even just getting to know students a little better in the contexts, chat gives it more of a kind of cohesive classroom environment. I mean you feel more an active part of class." (Interview, September 23, 2009)

Whereas she took a relatively reticent participant role in oral class discussions, Kelly seemed to display a variety of roles in online chat discussions such as respondent, commenter, informant, pivot, and questioner as shown in the above Table II When she was asked if there were any differences in terms of her involvement in, or response to, any of the four time synchronous discussions in which she participated, she reported:

"I found that they became more engrossing as the semester went on - partly because I was accustomed to the format and could really focus on the experience. I remember that I didn't want to stop when time ran out in the last two discussions. It was so dynamic and there was so much more we could have talked about. I felt that I was learning from my classmates. ... Synchronous was so much fun and so different from the usual mode of classroom dialogue that I definitely preferred it." (Self-reflective Essay, December 9, 2009).

As the above excerpt tells, she made a great personal transformation by adopting more dynamic roles shifted from the role of peripheral participant. The following example demonstrated Kelly's changing move toward full participation in online chat.

\section{Sequence 1.1}

\#39 04:10:52 PM

Rorita:

I am very interested in how to help students who are not succeeding to succeed. One way I was thinking about studying drop outs to see if goal orientation was a factor in their lack of success would be to test a group of $4^{\text {th }}-5^{\text {th }}$ graders on the goal orientations and then to follow them to see how they do. Do they succeed and move on and into college? Do they drop out early? And does their goal orientation explain their progress.

\#42 04:11:31 PM

Ming:

How long would you follow them, Rorita?

\#43 04:11:36 PM

Alicia:

Rorita: don't you run into the confounding issues of longitudinal studies, though?

\#44 04:11:55 PM

Ming: 
Yeah, you'll be in school forever. :-P \#45 04:12:03 PM

Mary:

Rorita: I'd imagine that goal orientation evolves as students grow through the grades- middle school alone brings a whole new set of challenges, especially when thinking about social goals.

\#52 04:13:03 PM

Rorita:

Yes, you would run into confounding issues and I would follow them at least into college so there would be many confounding variables. I haven't worked that out yet.

Ming's point is very important I thought. I also thought Pintrich's discussion of empiricism and his differentiating it from positivism was interesting.

\#55 04:13:21 PM

Dorothy:

Mary - that's exactly what I've thought - that as we get older, we're a little more on the mastery-orientation and a little less on the performance orientation, especially of the avoid type.

\#58 04:13:59 PM

Mary:

Dorothy: yes, especially when you're dealing with people who make the choice to enter graduate school After each online discussion, I collected the transcript of the online discussion. I examined the transcripts from a language socialization perspective and with the concepts of a community of practice in mind prior to the discoursebased interviews.

In Sequence 1.1, Rorita, taking the role of primary author, brought up her future plan to conduct research with a group of $4^{\text {th }}-5^{\text {th }}$ graders on goal orientations. Her turn was acknowledged by other participants' responses. As the interaction continued, Dorothy, the teacher, ratified Mary's comment about changes in goal orientation according to learners' development. Once the teacher ratified her contribution, Mary attempted to expand the topical point by adding a relevant example.

Sequence 1.2

\#57 04:13:55 PM

Jennifer:

Regarding the middle-school math example from class...I think that today, it isn't as likely to see girls avoiding the math courses...I believe Dweck originally did that research back in the 80 's, and then hypothesized why girls weren't continuing to achieve in middle school and beyond. At one point in time, there was research (not sure by whom) that it was the fact that teachers called on boys more than girls in class, which led to different expectations for boys v. girls, but I think Dweck's hypothesis about the messages children get through socialization is worth further study. :)

\#65 04:15:44 PM

Kelly:

I think there's a connection between those two comments about student orientations in grad school and middle school - teacher expectations - some graduate programs are more mastery-oriented while others are more performance-oriented, which may lead to attracting/retaining students with different orientations

\#66 04:16:17 PM

Jennifer:

Interesting point, Kelly...what do you think the focus is here at UT? \#68 04:16:33 PM

Rorita:

Kelly, I wonder if the $\mathrm{PhD}$ completion rate is lower in masteryoriented programs than in more performance-oriented programs

\#70 04:16:53 PM

Ming:
That's an interesting thought...

\#72 04:17:39 PM

Mary:

Kelly- I find that to be true- I just completed my MS at a program which also offered a EDD rather than a $\mathrm{PhD}$... which seemed to be more performance-oriented, less theoretical, more applicable

\#79 04:19:30 PM

Ming:

I think a lot of that depends on the context, however.

In this sequence, Kelly, in turn 65, was trying to connect middle school girls' preferred learning styles in a math class (Jennifer's turn 57) with learners' change in their goal orientation (the topic in Sequence 1.1) and then to propose her own perspective, which, as a result, pushed other peers to shift their moves to view the ongoing issues from a slightly different angle. Kelly functioned between the two flows of conversation but carried information from one predominant interaction to a slightly shifted topic across the participant groups. By indirectly referring to Jennifer's comment about the example of performance oriented girls in a math class, which was a continuation from the oral class discussion, Kelly made Jennifer's voice resonate through her comment to the conversation. By so doing, Kelly ratified Jennifer's attempt to gain access to the floor as appropriate participation, thereby redefining her status from an overhearer to an interlocutor. In a discourse-based interview, she articulated her role as pivot in her own words:

"I think there were two different comments regarding um ... I'm gonna see here but I think Dorothy here is responding to an earlier point where they were talking about how we become more mastery oriented over time, and then over here, you know, we were still talking about the middle school math example here. So Jennifer was talking about that. I think I was trying just to bring together two of the different areas we were talking about, and then thinking about how it might not necessarily be just something that changes as you get older in one direction, but that it really depends on what environments you were in. That's what I was thinking about at that point." (Interview, September, 23, 2009)

Thus, Kelly established herself in the role of pivot as she circulated the appropriated and integrated perspective of learner's goal orientation to Jennifer, Rorita, Mary, and Ming. She tried to share her understanding of goal orientation with group members, which was acknowledged by those members (e.g., "Interesting point," "That's an interesting thought," "I find that to be true ..."). In the role of pivot, as Kelly entered into interaction with Jennifer, Jennifer was able to change her participation status to primary interlocutor. It was not until Kelly's turn that Jennifer was ratified by the group when Kelly stated, "... there's a connection between those two comments about student orientations in grad school and middle school ..." (turn 65). Kelly expanded the nature of participation structure by expanding opportunities for Jennifer's participation.

We can see the same dynamic at work in the following excerpt taken from Kelly's fourth synchronous chat.

Sequence 1.3 


\section{04:00:11 PM}

Tony:

How might we apply the concepts discussed by Panofsky to the formation of social cliques in schools? How much of their formation is due to the social space enacted by teachers? How much is due to class distinctions?

11 04:00:56 PM

Tony:

And by class distinctions, I mean social class.

17 04:01:47 PM

Kelly:

hum, interesting...it does seem like cliques form outside of teacher intervention - but I suppose, by creating a more equal social space in the classroom, it might help the students interact that way outside the class.

30 04:04:40 PM

Betty:

Schools are set up in a way that promotes one cultural group over another one ... teachers are just one part of this larger social network that perpetuates this ideology. Things like textbooks also help codify current understandings about class, race, and gender.

\section{Sequence 1.4}

37 04:05:19 PM

Kelly:

Betty, it makes me think even of the physical structure of the school. I worked in a school where most of the students were of low SES and we had 28 classrooms located in portable buildings on school grounds ... so most of the kids actually went to class inside portables rather than inside the main school building (compared to other middle schools in the area which had around 3 or 4 classrooms in overflow portables) - it sent a message to the kids about how much they were valued in the school district, since they didn't even have a permanent building in which to go to school.

\section{04:08:03 PM}

Matt:

Kelly - I think that's a good (bad) example of a bad designed hidden curriculum.

53 04:09:17 PM

Jimmy:

Kelly, I do like your example because there is much to be said about physical space and how it can be used to create systems.

The ongoing topic in this discussion was mainly about the relation of learning to students' social class. As seen in Sequence 1.3, Tony took the role of primary author by inviting others' participation, which was followed by Kelly's response. Like Betty, Kelly took a peripheral respondent role by answering Tony's request for knowledge. In Sequence 6.6, she then shifted to a pivot role in her second turn as she brought in her personal experience into the conversational flow, furthering interactions between other overhearers such as Matt and Jimmy. By participating in two overlapping frameworks, she carried information from one primary interaction (Sequence 1.3) to another conversational structure (Sequence 1.4). Kelly's role as pivot was co-constructed among participants in their negotiated participation, as Larson [15] suggested: "these roles including pivot occur sequentially in the participation framework; that is, they are mutually constituted and emerge over time in daily interaction" (p. 285).

As reflected in her essay, Kelly clearly had positive feelings about the chat discussion mode. She conceivably brought a more worldly perspective to the discussion group, encouraging and engaging others. As a human agent with a strong sense of goals for "communicating like an educational psychology doctoral student," Kelly exercised her agency by taking the role of pivot, attempting to shape and construct the conditions and opportunities for her learning in the synchronous CMC activity.

4.2.2 Rua's Perspectives and Interactional Strategy: Although Rua found synchronous CMC activity more challenging than oral discussion in the class, she reported that she did not experience any "feelings of anxiety or dread" when she was posting her comments in synchronous chat sessions. In contrast to Kelly, however, Rua's perceptions about her changing involvement in the synchronous chat were not as positive. She reported: "I think they were all pretty hard. I don't feel I made a big improvement from the first one to the last one" (Self-reflective Essay, December 9, 2009).

Rua consciously used an interesting interactional strategy to interject her comments during synchronous discussions. The strategy was to pose a related question in the middle of or at the very end of her comments in order to involve other peers. Most often, when she negotiated meaning of particular course concepts, she employed requests for help as well as clarification and comprehension checks.

The questioner role taken by Rua was illustrated in the following excerpt from her first synchronous chat that occurred on September 16. The topic that participants were discussing was about an article about college student-athletes' motivational sense of self.

\section{Sequence 1.5}

30 04:13:02 PM

Dorothy:

One thing I thought we'd discuss here is the last of the 3 articles we read for today. I'm very curious as to what you thought of the studentathletes and the model Wilson \& Smith created.

36 04:13:47 PM

Matt:

I have found it to be quite interesting - especially when I draw from my own experience as a student-athlete. I was especially drawn to the "brought to play/study" athletes.

38 04:13:54 PM

Betty:

Dorothy - I found the student athlete article fascinating.

Particularly the way the authors classified the students into the different groups and then looked at their expectancy and value motivations.

40 04:14:05 PM

Dana:

I found it interesting how the student athletes each came to a decision about what was important and how to balance - or not balance each activity.

41 04:14:20 PM

Mary:

Dorothy: re: student-athletes, I thought it was fascinating to see a clarification of how motivation and the self was interwoven, and how the sense of self competence would transfer to another domain if challenged in one domain

44 04:14:42 PM

Joe:

I would be interested to see how a larger sample of student-athletes would have broken down in the 2-dimensional framework established 
in the paper.

45 04:14:57 PM

Jimmy:

I found the grouping interesting as well. It would be interesting to see different exams run on each group to see differences and similarities.

48 04:15:45 PM

Rua:

I thought it was a very interesting article that gave a clear example of motivation theory, yet could some one tell me exactly what motivation theory does it represent? It has a lot of goal orientation, I believe, but also some extrinsic and intrinsic motivation.

85 04:21:52 PM

Dorothy:

Rua - you were asking about the student-athlete article, right? They saw it as most related to a self-determination perspective, even though you are right, they did talk about goals. But, the goals they were referring to were not the achievement orientation goals that Dweck was talking about.

As the above data segment indicates, Dorothy, the teacher established the first turn by initiating a particular topic regarding one of the articles on student-athletes and the model that the authors had developed. A few students almost simultaneously responded to her request for their ideas and opinions, which shows the multiplicity of synchronous CMC writing. As Rua mentioned that she is a slow reader during her first interview, she posted her turn relatively later than other students. In the middle of her turn, Rua posed a question to engage other peers so that she could be ratified ("could some one tell me exactly what motivation theory does it represent?", turn 48) as a group member. Dorothy responded to Rua by echoing Rua's voice ("you were asking about the studentathlete article, right?"), and offered her assistance to help Rua's understanding about the topic ("But, the goals we were referring to were not the achievement orientation goals that Dweck was talking about") in turn 85. Once Dorothy's attention was displayed, Rua seemed to shift to the role of active interactant by contributing to the topic development.

In her second participation in a synchronous chat session held on October 7, similar interaction patterns were identified consecutively. The initial part of the chat discussion demonstrates that Rua was negotiating the meaning of a key concept schema with other peers.

\section{Sequence 1.6}

9 04:07:59 PM

Rua:

Hello

15 04:09:56 PM

Rua:

I had a question about the schema-is this the same as our "mental scenario"?

29 04:13:07 PM

Eunjoo:

Hi, Rua

I think schema is similar concept to our mental scenario. What I understood is that we use our schema to construct new knowledge.

32 04:13:32 PM

Dorothy:

Rua - yes, such a good connection between scenario and schema. So it's not that they're exactly the same. In fact, you use your schema to construct the scenario you build to represent your understanding of the current situation. So the schema represents your prior knowledge, or IS your prior knowledge, from which you build the scenario.

36 04:14:03 PM

Rua:

Eunjoo, that is so interesting, I relate to this in my stats class (it is introductory) yet I had a difficult time understanding the first part of it. Professors in graduate degree don' t scaffold any more or at least that is my perception. We have to do it elsewhere. Yes?

44 04:15:21 PM

Rua:

So schema is like the most basic mental construct someone can have?

52 04:16:46 PM

Dorothy:

Rua - a schema is like the abstraction you can construct out of repeated experiences with something. That's what represents your prior knowledge.

4.2.3 Lynn's Perspectives and Negotiation: Lynn's reaction to online chat appeared to give a somewhat conflicting account to previous L2 studies that showed some evidence of learners' reduced anxiety in online chat experiences. It seemed that synchronicity and simultaneity of online chat mode generally caused her a "sense of anxiety" and that, as a result, she was "completely lost and had no idea" of what she needed to do in engaging in the online chat. When she was asked about any perceived difficulties in participating in the online discussions as a non-native speaker, she said:

"Um mm ... I don't know because I would consider my ... I've never thought about that kind of question before, but I would consider myself as kind of like a slow person, because every time when I have to respond a question or whatever, it takes me time to think about that. So, I really have no idea if it's because of the language because I'm not a native speaker, or it's just because of my personality. I would say it's because of both language barrier and my personal orientation ... Probably ...Yeah..." (Interview, September 25, 2009)

As Lynn regarded herself as "a slow person," her individual orientation to a relatively slow rate of processing may not have been a good fit for synchronous chatting but a much better fit for the asynchronous Blackboard discussion.

Although she felt that she needed to adjust to the fast onslaught of topics in the synchronous discussion to survive in the course, Lynn could not figure out in the first chat any coping strategy to be included or manage the online chat. The teacher's feedback after the first synchronous discussion became an important turning point for her personal transformation in online chat participation. Her change was manifested in her self-reflective essay as follows:

Even though I tried to respond to the statement that draw my attention or I had a strong reaction to it, I erased it right away because once I finished typing my statement, there were many new statements posted within seconds - so at that time, I thought it was not a good idea responding to a question or statement that was already found somewhere on the screen. However, after our first session, the professor encouraged us not being afraid of posting any statement even if it was late (I found her comment useful). So I was able to get involved more 
in other synchronous discussions afterwards. (Self-reflective Essay, December 12, 2009)

There was a large difference in the variety of roles she took on in participating between her first online chat and the other online chat sessions in which she was involved. Of Lynn's 24 postings excluding the initial salutations, 12 postings included agreement with the previous speaker (e.g., "I agree," "I do, too," "it's true," "that's true - I agree," "I do agree with you," "I am surprised, too," "and I cannot agree with you anymore"). Superficially, she frequently performed the role of agreer possibly in order to be acknowledged by her fellow interactants.

The best example taken from her first online chat demonstrates her role as agreer:

\section{Sequence 1.7 \\ \#14 04:07:43 PM \\ Lynn: \\ hello \\ \#41 04:11:18 PM \\ Dorothy:}

I am so happy to see you all here. So yes, let's talk about Sidiridis. So what did you think of the EMOTIONS he saw as related to the different goal orientations? A little predictable but so nice that he thought of that, I thought.

\#48 04:12:19 PM

Nick:

it would be hard to talk about motivation without addressing emotion, i think.

\#51 04:13:03 PM

Lynn:

I agree with Nick.

\#74 04:18:02 PM

Nick:

In a foreign language, I might be high performance-approach for writing and high performance avoid for speaking

\#78 04:19:08 PM

Lynn:

I agree, especially for adult learners, they are high performanceapproach for writing and reading than speaking and listening.

In the above sequence, Lynn's role of agreer to the previous speaker, Nick, was manifested two times. In turn 51, she picked up Nick's response to Dorothy's topic initiation simply by saying, "I agree with Nick." Once again, in turn 78, she took the role of agreer ("I agree") and then used the opportunity to draw an inference from Nick's posting about adult learners' tendency to adopt a performance-approach orientation in their learning. In so doing, Lynn's role was clearly that of agreer in the first online chat. In this role, she could participated peripherally in the first session without affecting the main flow of topic distribution.

In the second online chat held on September 30, however, she showed some variation in her role within the participation framework, suggesting that she was being enculturated into a new academic cultural production, that of online chat. Lynn not only performed the role of agreer but also played the role of questioner, informant, and challenger. It seemed that she aligned with, questioned, expanded, and challenged the knowledge posted by others depending on the evolving participation structure.
The following sequence taken from the second online chat demonstrates her changing roles.

\section{Sequence 1.8 \\ 10 04:12:12 \\ Lynn: \\ Hello \\ 24 04:14:55 \\ Alicia:}

Did anyone else have negative feelings regarding the handwriting article?

34 04:16:17

Dana:

I loved the handwriting article! It reminds me why people get so aggravated by websites that are non-intuitive. They don't have any bandwidth left to learn anything anymore.

36 04:16:39

Lynn:

I do, too. I like the handwriting article.

38 04:17:00

Dorothy:

Ah. I love this connection between the topic for today and what we're doing right now. SO SO much overload when we're in here. Hard to imagine that a person could fall asleep. But then, you can see how it would happen if you decided that you had to give up and not try to participate.

42 04:18:00

Yang:

Dorothy

I read Chinese too. During the activity, I found myself to read the Chinese character faster in mind than reading it out loud. It seemed less distraction. I think it's kind of interesting.

50 04:19:07

Lynn:

So, Yang. When you read the poster, did you find it hard to ignore the Chinese characters?

55 04:20:11

Lynn:

Yang - it was so hard for me not to pay attention to the meaning of the words. Even though I kept telling myself to ONLY focus on the colors.

62 04:21:06

Yang:

Lynn,

I did, esp., the very first characters, but we get better very quickly, do you think so? It's like once you know the rule, you go with the flow. 72 04:22:50

Lynn:

Yang - probably you're right. But, I wonder the speed for me to either read English or Chinese words would be different? What do you think?

88 04:25:34

Yang:

Lynn,

I think it also depends on how long you have been exposing in English. I learned my ABC since 13. And you?

110 04:31:15

Lynn:

Yang, 13 ... so that is a junior high school level. But, many parents in Asia tend to send their young kids to an after-school program to learn English. I think it's probably related to how often you use the language, right? So, how long have you been here?

118 04:33:11

Yang:

Lynn,

I didn't have any those after-school English classes, because our 
teacher forced us to attend her Chinese after- school class.

In the above sequence, in turn 34, Dana developed a "primary dyad" [27] by responding to Alicia's question. In turn 36, Lynn took the role of agreer to Dana's comment by saying, "I do, too." She then shifted roles and moved to the role of questioner in a way to respond to Yang's posting about reading the color of Chinese characters, an activity that had been done in class immediately prior to the synchronous chat. In turn 72 , displaying her agreement with Yang's comment ("you're right”), Lynn also played the role of questioner to seek Yang's response in comparing the speed of reading English and Chinese ("What do you think?"). In turn 110, as a way of responding to Yang's turn 88, Lynn posed another question to seek information (“So how long have you been here?"), which was then followed by Yang's response (turn 118).

\subsection{Summary}

In summary, the framework of participantion structure grounded in Goffman [26] and Larson [27] allowed for identifying L2 students' academic discourse socialization by means of types of participant roles. Data analysis highlighted moment-by-moment changes in the participation framework that are brought about by the ways the participants use turntaking in online chat.

First, several participant roles were identified in synchronous chat activity: primary author, respondent, agreer, commenter, questioner, challenger, and pivot. Shaped by the focal students' personal history and desires, their roles were negotiated in varied ways within the multilayered participation structure.

The role of pivot taken by Kelly, for example, was used as a starting point for a new interpretation of the ongoing topic by heretofore reticent group members as additional frameworks emerged in the synchronous chat. That is, participants drew on the information offered by the pivot as a resource for their own statements. While Kelly renegotiated and exercised her agency by taking the role of pivot, Rua frequently adopted the role of questioner, preserving her ethnic identity. It is interesting to note that Rua's cultural identity, to some extent, moderated her role in the participation framework. Rua associated her identity with that of a collectivist culture as shown in the following interview:

I think that in a collectivist culture, well at least in Mexico, we are used to sharing knowledge with everyone, we're constantly looking for people to agree with what we say. When I put my question mark because I want to learn a global thinking to know what my peers think, what they think about what I'm saying, then, I will reconstruct my knowledge. I would say that is more like individualistic. And then in collectivism, this is what I think and I am opening it to the discussion. That's kind of what I want to say. (Interview, December 16, 2009)

Rua's cultural identity based in collectivist culture of Mexico, in part, contributed to the role of questioner that she performed in order to develop a symbiotic relationship with other members. In contrast to Kelly and Rua, Lynn reported that she experienced feelings of loss during the first online chat because she was overwhelmed with a number of comments appearing on the screen. As her 12 postings indicated, Lynn frequently turned to the role of agreer to be acknowledged by her group members.

Second, the students were able to employ the interactional resources that they had in their repertoire during synchronous chat. The configuration of the interactional resources includes the resources related to turn and topic management.

For instance, Rua, by taking the role of questioner, heavily relied on requests for clarification to have her turns validated. As for Lynn, the role of agreer allowed her to display her agreement with prior turns as response tokens to generate adjacency pairs. Since interactional competence comprises the interactional resources that participants can use in social interaction, it is reasonable to argue that the students developed interactional competence that is essential part of discourse socialization as they legitimately participated in synchronous chat.

\section{CONCLUSION}

In this description of how three focal participants each negotiated the online chat, I hoped to present how they took different paths in becoming part of a new cultural norm as represented by the activity of an academic online chat.

Novice graduate students from diverse backgrounds need to be socialized and enculturated into graduate academic discourse and professional discourse [15]. Given that such socialization generally occurs through face-to-face courses, it was important to examine how novice graduate students participate in online chat for academic socialization to occur.

Through my analysis, I aimed to show that the students produced roughly the same number of online written postings in the synchronous chats. Overall, the findings of the study revealed the multiple dimensions characterizing the process of academic discourse socialization when a student is learning in an educational environment that uses a language other than the student's native language.

However, qualitatively, their individual perspectives on the synchronous CMC activity and their roles of participation seemed noticeably different. This difference does not necessarily indicate that Kelly's negotiation in the online chat was superior to Rua's or Lynn's. Shaped by their personal history and desires that Kelly, Rua, and Lynn brought into online chat sessions, their roles were co-constructed in varied ways within the multilayered participation structure. The notion of gaining access to fuller participation in the online chat is connected to as legitimate peripheral participation what Lave and Wenger [2] referred to. Changes in the focal students' role toward more intensive participation constituted learning trajectories and forms of membership [2].

The findings of the study imply that synchronous CMC can be worthwhile communities of practice as extensions of onground, face-to-face academic discourse socialization and could be fully utilized by students and professors. Also the findings of showed that discourse socialization is a complex, dynamic process of co-construction and negotiation, supporting other researchers' recently reported qualitative studies (e.g., [23], [28], [29]). 


\section{ACKNOWLEDGMENT}

This research was supported by a 2013 Research Grant from Sangmyung University.

\section{REFERENCES}

[1] J. P. Lantolf, Sociocultural theory and second language learning. New York Oxford University Press, 2000.

[2] J. Lave, and E. Wenger, Situated learning: Legitimate peripheral participation. Cambridge, MA: Cambridge University Press, 1991.

[3] M. Lampert, "When the problem is not the question and the solution is not the answer: Mathematical knowing and teaching", American Educational Research Journal, vol. 27, 1990, pp. 29-63.

[4] J. M. Swales, Genre analysis: English in academic and research settings. Cambridge, England: Cambridge University Press, 1990.

[5] N. Mercer, Words and Minds: How We Use Language to Think Together, London: Routledge, 2000.

[6] P. Prior, Response, revision, disciplinarity: A microhistory of a dissertation prospectus in sociology. Written Communication, vol. 11, 1994, pp. 483-533.

[7] S. Paavola, L. Lipponen, and K. Hakkarainen, "Models of Innovative Knowledge Communities and Three Metaphors of Learning," Review of Educational Research Winter, vol. 74, no. 4, 2004, pp. 557-576.

[8] J. S. Brown , A. Collins, \& P., "Duguid, Situated cognition and the culture of learning," Educational Researcher, vol. 18, no. 1, 1989, pp. 32-42.

[9] N. Morita, "Discourse socialization through oral classroom activities in a TESL graduate program," TESOL Quarterly, vol. 34, 2000, pp. 279-310.

[10] L. Vygotsky, Mind in society: The development of higher psychological processes. Cambridge, MA: Harvard University Press, 1978.

[11] J. S. Brown, and P. Duguid, The Social Life of Information. Boston, Massachusetts: Harvard Business School Press, 2000.

[12] D. Belcher, D., and G. Braine, Introduction. In D. Belcher \& G. Braine (Eds.), Academic writing in a second language: Essays in research and pedagogy, Norwood, NJ: Ablex,1995, pp. xiii-xxxi.

[13] P. Prior, Writing/disciplinarity: A sociohistoric account of literate activity in the academy. Mahwah, NJ: Lawrence Erlbaum, 1998.

[14] C. P. Casanave, Writing games: Multicultural case studies of academic literacy practices in higher education. Mahwah, NJ: Erlbaum, 2002.

[15] C.P. Casanave, X. Li, and J. Swales, Learning the literacy practices of graduate school. Ann Arbor, MI: University of Michigan Press, 2008.

[16] M.-C., Ho, "Academic discourse socialization through small-group discussions," System, vol. 39, no. 4, 2011, pp. 437-450.

[17] A. M. Blakeslee, "Activity, context, interaction, and authority: Learning to write scientific papers in situ,"
Journal of Business and Technical Communication, vol. 11, no. 2, 1997, pp. 125-169.

[18] Y. R. Dong, "Non-native graduate students' thesis/dissertation writing in science: Self-reports by students and their advisors from two U.S. institutions," English for Specific Purposes, vol. 17(4), 1998, pp. 369390.

[19] A. Hirvela, and D. Belcher, "Coming back to voice: The multiple voices and identities of mature multilingual writers," Journal of Second Language Writing, vol. 10, no.1-2, 2001, pp. 83-106.

[20] M. Warschauer, and T. Matuchniak, "New technology and digital worlds: Analyzing evidence of equity in access, use, and outcomes," Review of Research in Education, vol. 34, no. 1, 2010.

[21] Q. Lin, "Student satisfaction in four mixed courses in elementary education program," Internet and Higher Education, vol. 11, no. 1, 2008, pp. 53-98.

[22] S. Naidu, "Editorial," Distance Education, vol. 31, no. 1, 2010, pp. 1-3.

[23] G. H. Beckett, C. Amaro-Jiménez, and S. Beckett, "Students' use of asynchronous discussions for academic discourse socialization," Distance Education, vol. 31, no. 3, 2010, pp. 315-335.

[24] M. R. Hawkins, "Becoming a student: Identity work and academic literacies in early schooling," TESOL Quarterly, vol. 39 , no. 1 , 2005, pp. 59-80.

[25] D. Suthers, "Technology Affordances for Intersubjective Meaning-making: A Research Agenda for CSCL," International Journal of Computer Supported Collaborative Learning, vol. 1, no. 2, 2006.

[26] E. Goffman, Frame analysis. Harmondsworth: Penguin, 1975.

[27] J. Larson, "Talk matters: the role of pivot in the distribution of literacy knowledge among novice writers," Linguistics and Education, vol. 7, no. 4, 1995, pp. 277302.

[28] S. Zappa-Hollman, "Academic presentations across postsecondary contexts: the discourse socialization of nonnative English speakers," The Canadian Modern Language Review, vol. 63, no. 4, 2007, pp. 455-485.

[29] Y. K. Yim, "Second Language Students' Discourse Socialization in Academic Online Communities," Canadian Modern Language Review, vol. 67, no. 1, 2011, pp. 1-27.

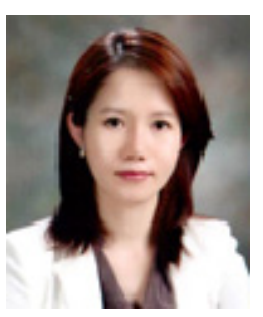

\section{Myung-Jeong Ha}

She received her $\mathrm{PhD}$ in Applied Linguistics from University of Texas at Austin. Her research interests are computer-mediated communication, computer-assisted language learning, and corpus linguistics. She is currently Assistant Professor in the department of English Language and Literature at Sangmyung University. 